\title{
Towards Knowledge-Sharing and Learning in Virtual Professional Communities
}

\author{
Michael Bieber ${ }^{1}$ \\ bieber@njit.edu \\ http://www.cis.njit.edu/ bieber
Il Im Im $^{1}$
ilim@homer.njit.edu
http://www.cis.njit.edu/ ilim \\ Ron Rice $^{3}$
rrice@scils.rutgers.edu
http://scils.rutgers.edu/ rrice/
}

\author{
Ricki Goldman-Segall ${ }^{1}$ \\ ricki@njit.edu \\ http://www.merlin.ubc.ca/people/ricki/
}

\author{
Ravi Paul ${ }^{1}$ \\ paulr@homer.njit.edu \\ http://www.cis.njit.edu/ paulr/
}

\author{
Edward Stohr ${ }^{4}$ \\ estohr@stevens-tech.edu \\ http://www.stern.nyu.edu/ estohr
}

\author{
Starr Roxanne Hiltz ${ }^{1}$ \\ hiltz@adm.njit.edu \\ http://eies.njit.edu/ roxanne \\ Jennifer Preece ${ }^{2}$ \\ preece@umbc.edu \\ http://www.ifsm.umbc.edu/ preece/ \\ Murray Turoff $\mathbf{f}^{1}$ \\ turoff@adm.njit.edu \\ http://eies.njit.edu/ murray
}

${ }^{I}$ New Jersey Institute of Technology ${ }^{2}$ University of Maryland at Baltimore County

${ }^{3}$ Rutgers University ${ }^{4}$ Stevens Institute of Technology

\begin{abstract}
This paper describes a program of research designed to understand how knowledge-sharing and learning can be supported in virtual communities. To conduct this research, we propose the development of a series of knowledge sharing tools and procedures followed by a rigorous evaluation of the use of these tools in real virtual community environments. The paper starts with a brief examination of relevant theory in knowledge management and learning. This leads to a comprehensive set of research questions. To investigate these questions, we next propose a set of tools for supporting collaboration, knowledge sharing and learning for distributed communities. Evaluation is also a vital element of this research.
\end{abstract}

\section{Keywords}

virtual communities, knowledge sharing, learning

\section{Introduction}

Our research aims to increase knowledge-workers' effectiveness by helping them share knowledge and learn through participation in virtual communities. Virtuality has several definitions. For some, it indicates distance, requiring collaborators to communicate asynchronously ("different time, different place"). For some, it expresses the ability of computers to represent information in ways different from reality, with new tools allowing a broad range of different people to understand complex or conceptual information and participate in exploring it (Turoff 1997). For some, it indicates an organizational (or community) structure that is flexible enough to optimize individual and group performance under new and changing conditions (Mowshowitz 1995; Robey et al., 1998). For some, it creates a sense of sharing experiences and perspectives, and emotional support between people working towards similar goals or solving problems together (Goldman-Segall 1998, Sproull and Kiesler, 1991). In our view, participation in virtual communities should involve all these characteristics. (Virtuality also carries the notion of 3-D immersion and simulation though our proposed research does not address this notion.)

The World Wide Web opened up new possibilities for people to collaborate. Even so, knowledge-workers and society are not benefiting nearly as much as they could from access to other people and knowledge (Preece 2000). Properly supported virtual communities could benefit society through collaboration and knowledge-sharing in ways not yet articulated. To realize this objective, we need to investigate how to design and manage virtual communities to promote knowledge-sharing and learning by individuals, groups and the community as a whole. We believe that the best way to do carry out this investigation is through action research, in which an environment of integrated tools is introduced and evaluated in an actual virtual community.

In this paper, we describe a set of tools for community knowledge, learning and sharing support, which we call C-KLASS. These tools provide a vehicle for examining community development and participants' interactions. We believe that existing academic professional societies will make ideal testbeds for evaluating these tools and 
learning how to use them. These societies consist of virtual communities of researchers, practitioners, students, teachers and organizations who participate to better understand its domain and improve their own professional standing. The virtual community of a professional society includes non-members and organizations and can be thought of as an extended community of practice. Professional societies already have an organizational infrastructure in place to work with the researchers, and to develop, maintain and support the prototype system. The ultimate test of such an environment of tools and associated best practices will be its adoption by other virtual communities. Once it has evolved and proven its usefulness in testbed communities, we propose to make the C-KLASS environment freely available to any virtual community.

We begin with a discussion of knowledge-sharing and learning in virtual communities. The existing literature motivates our research questions and also provides guidelines for the kinds of activities and processes that should be supported in a virtual learning community. We then identify some key research questions that we intend to address. Next we discuss our approach and how we would work with testbed communities. We then describe the integrated set of tools we shall prototype, the process of our investigation, and our evaluation plan. We conclude with a review of our contributions and speculate on the broader impact of this research.

\section{Knowledge Sharing and Learning in Virtual Communities}

Research confirms that knowledge acquisition and learning are greatly facilitated by interaction and collaboration with others (e.g., Vygotsky, 1962; Wenger, 1998). Virtual communities have the potential to greatly enhance how this occurs, but their long-term success can be problematic, as discussed below.

\section{Knowledge and Community}

Much of a community's knowledge lies within its documents, discussions, decisions, conceptual models, formal educational modules, processes, and the awareness by members of other members' expertise (e.g., Rice et al. 1999). For an academic professional society, community documents include books, journal articles, conference papers, audio tapes, videos, still pictures, course syllabi, and tutorials. (This is far beyond the mandate of electronic databases such as the ACM Digital Library.)

Community knowledge also includes the links (relationships) among all these elements and documents, including relationships among community members.
Techniques such as automated indexing and dynamic hypertext (Bieber 1998) can help develop the document linkages and support navigation by users through the resulting knowledge base. Member relationships can be automatically deduced based on expertise profiles, coauthorship, citations, and mentions within threaded online discussions, etc. Other techniques, such as network analysis, have been used for related purposes (e.g., Wellman, 1997). Analysis of other community knowledge resources could yield additional inferences.

Many of these knowledge types could be made explicit and accessible given the appropriate computerized tools. Collectively this knowledge constitutes a community memory of past experiences, considerations and decisions that knowledge workers, community leaders and other members can explore. However, such community memories are notoriously difficult to maintain over time, suggesting that processes and incentives for community knowledge maintenance is an important research topic.

The knowledge management literature distinguishes between individual versus organizational (and by extension, community) knowledge. Knowledge may only exist through social cognition. Organizations and individuals may influence the development and maintenance of knowledge at each level (Walsh \& Ungson, 1991). Further, knowledge may be tacit, cultural, or not expressable for many reasons (Choo, 1995, 1998; Nonaka 1994), or may be articulatable or explicit (Davenport \& Prusak, 1998), such as 'know-how', 'know-why' and 'know-what' (Sanchez, 1997). Processes that mediate between tacit and shared explicit knowledge include socialization, externalization, combination and internalization (Choo, 1995; Nonaka 1994).

Four types of organizational (community) knowledge may be derived from an individual/social dimension and an explicit/implicit dimension (Spender, 1998).

Individual/explicit is "conscious". Individual/implicit is "automatic". Social/explicit is "objectified".

Social/implicit is "collective". Of particular significance is objectified knowledge. It represents a "single, rigorously structured and coherent discourse" (Spender, p. 240), but is the most difficult to manage and foster, being derived from and requiring collective knowledge.

Collective knowledge is inherently a public good - it is not diminished by distribution, can be reapplied within the organizational system, and allows access to greater diversity of interpretations as responses to uncertainties. Paradoxically, collective knowledge usually has no value when controlled solely by individuals (and then no longer is a public good). 
Social network theory argues that people develop their shared attitudes, norms or behaviors through exposure to proximate others in a social network (Wellman, 1983). Through networks, individuals exchange information, vicariously experience others' behaviors, legitimate changes and reduce uncertainty about an event, idea or phenomenon. According to Cicourel's (1990) socially distributed cognition, shared problem definition and information transfer generate new and increasingly complex knowledge, both in response to known problems, and through discovery or definition of new and neglected ones. Hutchins (1991) conceptualized "cognition as embodied within the context in which it occurs...distributed across individuals and the setting." Community members can draw on this resource, which then becomes a "public good" (Kollock, 1999). Virtual communities may facilitate this distributed cognition by reducing the dependence on being in the same place at the same time, that is, by extended the conditions under which relations may be more "proximate".

We believe that explicit community knowledge can be supported by managing a broad array of information and developing suitable knowledge representation schemes. The internalization and socialization processes associated with the implicit knowledge of individual community members can be supported by the learning aspects discussed next.

\section{Learning and Community}

Learning is a constructionist, often social activity occurring through knowledge building (Vygotsky, 1962). Knowledge building activities include contributing to, authoring within, discussing, sharing, exploring, deploying a collective knowledge base (O'Neill \& Gomez 1994; Perkins 1993). People learn as they navigate to solve problems (Koschmann et al, 1996) or design representations of their understanding (Suthers 1999). Learning requires cognitive flexibility (Spiro et al. 1991), and results from interaction with people having different experiences and perspectives (Goldman-Segall et al. 1998). Much learning between and within communities occurs with boundaries rich in interactions, whether formal, informal, or through a computer based system (Wenger 1998).

Similarly, the processes used by virtual learning communities also can be improved. Student-centered teaching theories (McCown \& Driscoll 1995) state that students learn through collaboration, but they rarely meet and work with students beyond their own school or university. Scaffolded learning theory states that real-life experiences and case studies would enrich research and studies (Linn 1995). In a virtual community, teachers could have a mechanism for involving practitioners with their classes as well as encouraging peer-to-peer interaction.
From the above, we conclude that research is needed on how virtual communities can be structured to provide the processes and incentives needed to promote active learning and collaborative interaction, and to provide easy access to appropriate experts both within and external to the virtual community.

\section{Virtual Communities}

To be sustainable over time, virtual communities need a clear purpose (Preece, 2000) and sufficient social value (users, information, resources) to stimulate continued adoption, use, and contribution by a critical mass. Several studies have begun to deal with variations of this difficult problem, such as contributions to collective databases (Connolly \& Thorn, 1990), sharing of solutions to organizational problems (Gilly, Stevenson \& Yale, 1991), motivations for posting to bulletin boards (Rafaeli \& LaRose, 1993), diffusion of electronic mail systems (Rice, 1990), and collecting and providing access to organizationallyrelevant individual expertise (Stevenson \& Gilly, 1993; Stein \& Zwass, 1995).

Scalability also must be addressed (Brown et al., 1999). Several participating testbed communities have large memberships. These broad communities include students with no experience, practitioners with no formal education, people not conversant in the community's dominant language, government policy makers, educators and researchers. The current generation of collaborative tools and structures break down when large groups (e.g., class sizes over 50) use them for intensive information gathering and analysis (Turoff et al. 2001). A 20 member project management group discussion can generate $10,000+$ comments per year, and quickly become disorganized without trained indexers. Providing large-scale effective user interfaces becomes an important aspect of supporting an integrated knowledge environment for diverse communities. A key issue is knowing what size critical mass is needed for a healthy community at any time (Preece, 2000).

With a critical mass of community participation, effective structuring, seamless access, and repeated experience, community members (researchers, teachers, students, practitioners and related organizations) will improve the way they acquire knowledge and accomplish tasks.

\section{RESEARCH QUESTIONS}

A virtual community structure should foster knowledge sharing and learning so that individual members, as well as the collective community, are more effective, in a sustainable way. There are several difficult and critical issues for virtual communities in general, and the 
communities surrounding professional societies in particular.

\section{(A) Virtual Community Structure}

(A1) What formal and informal structural components characterize an active, healthy, virtual learning community?

(A2) How should virtual communities be structured to promote knowledge-sharing and learning, and increase the size and stability of their membership?

(A3) How can we adapt current or develop new technologies to support the appropriate structural components?

\section{(B) Knowledge and Learning}

(B1) How do different members of a virtual community create, understand, reuse, and learn from knowledge?

(B2) What kinds of knowledge and memory should be supported in virtual communities?

(B3) How do the kinds of knowledge and learning supported by virtual communities improve the effectiveness of members' everyday activities?

(B4) How can we support knowledge-sharing, learning and memory?

(C) Making Virtual Communities and Individual Participants and Groups More Effective

(C1) What kinds of activities do individual community members and groups undertake that are related to the community's purpose?

(C2) What barriers exist to knowledge-sharing and learning, and how can these be lowered?

(C3) What kind of interfaces and new media could support and improve community-related activities by individuals and groups?

\section{(D) Sustainability and Scalability}

(D1) How best does a community announce and advertise C-KLASS' goals, features and services?

(D2) How will a critical mass of community members come to "buy into" C-KLASS, add materials to it, and use the system to access the community's own information?

(D3) How do we scale the systems supporting virtual communities and their broad membership?

(D4) How best should a community manage C-KLASS?
(D5) What factors best predict on-going sustainability of virtual communities?

(D6) How best do we provide on-going feedback to both implementers and participants so that they can better manage and sustain the community?

We contend that these research questions can best be addressed by studying several testbed virtual communities, both before and during the staged introduction of support software such as the C-KLASS system described below. Through studying both the social and technological aspects of virtual community support, we plan to gain important insight on each of these research questions.

\section{C-KLASS: Support for a Virtual Learning Community}

Educational researchers have developed communitybased systems for student and researcher learning. Web Constellations (Goldman-Segall 1998), for example, allows people to view and annotate video data on-line and participate in community-theory building. Knowledge Forum or "CSILE" (http://csile.oise.utoronto.ca/) enables students and their teachers to build large databases of information and viewpoints on specific topics they are studying. Knowledge Integration Environment (http://www.kie.berkeley.edu/) acts as a coordinating body for researchers, stakeholders, schools and learners. The MERLOT digital library (http://www.merlot.org/) and several other more fledging groups (e.g.,

http://www.smete.org/nsdl/projects/) are building collections of educational modules in various domains.

Yet, no existing approaches address the full range of knowledge repositories, and knowledge sharing and learning processes discussed earlier. For example, most group support technologies focus on relatively simple forms of communication for conferencing, passing messages and routing documents. The advanced structures needed for large dispersed groups to effectively work together on a variety of issues using a range of media forms do not exist (Majchrzak et al. 2000; Turoff et al. 1999). Research on digital libraries, which could store and give access to all aspects of community knowledge, primarily concerns archiving and retrieving documents, though some community services such as peer review and annotation are being researched (Borgman 1999; Kling 1996). Little work has been done on the workflow systems that are flexible enough to capture and support work processes in large communities outside formal organizations. Also, researchers are only now beginning to study the ad hoc workflows that could benefit informal groups (Bernstein 1998; Zhao et al. 2000). User interface design of broadly accessible systems still seems to shut out 
many potential members of society (Rice et al. 2001; Shneiderman, 2000). Learning systems are not structured adequately yet to serve large diverse virtual communities of content producers and learners. Furthermore, despite the plethora of computer-supported collaborative learning systems (O'Neill \& Gomez, 1994; Scardamalia et al. 1992; Stahl, 1999), only a few researchers have been concerned with how individuals build knowledge based on a variety of perspectives (Goldman-Segall et al 1995; 1998). Hypermedia systems primarily concentrate on manually constructing links and other services among documents (Bieber et al. 1997). Few hypermedia systems provide linking for other kinds of organizational knowledge and none enable interlinking the range of knowledge components as we propose here. Similarly, no systems provide integrated access to the range of knowledge components and media types we believe virtual communities need.

To facilitate knowledge sharing and learning, we propose an initial set of integrated tools for virtual community support, which includes (1) computer-mediated communication (Turoff et al. 2001), (2) conceptual knowledge structures (Bieber et al. 2002, Turoff et al. 1999), (3) advanced hypermedia features (Bieber et al. 1997), (4) community process support (Bieber et al. 2002), (5) digital video for collaboration, learning, and (6) financial transaction support. The integration of these components will represent a major advance (Gaines et al. 1997; Preece 1999). Whenever possible, we propose the use of existing technologies and systems and emerging WWW standards.

\section{Digital Video}

Digital video opens up new possibilities for synchronous and asynchronous collaboration and learning. Video can save time in communication. It can represent knowledge in ways no other medium can. Huge video databanks exist with no real methods for processing and utilizing them within virtual communities (or otherwise). While video has the draw-back of requiring participants to be co-present, it appears to help support trust development between people who meet for the first time, which makes later asynchronous textual communication easier (Bos et al., 2001).

\section{Financial Transaction Support}

Community support is not always free. Companies, universities and professional societies often charge for services, including basic membership, professional development and learning modules, and access to proprietary and copyrighted materials (Hagel and Armstrong, 1997). The proposed environment will incorporate financial transactions seamlessly. In fact, C-KLASS should enable the formation of a marketplace to provide information and support learning processes around learning modules such as training courses and seminars. This marketplace can help form the glue for the larger community to coalesce.

Virtual communities could take advantage of many transaction mechanisms for better knowledge sharing and learning. Transactions may concern physical products, services, or knowledge. The ability to earn money or credit will make additional knowledge and learning resources available. Some virtual community-specific transactions can support better community management. For example, in order to promote contribution of members to knowledge creation and sharing, the contribution of each member could be measured and rewarded in some way. Previous studies have explored several methods for evaluating the contribution of members - auctions for knowledge goods on-line reviews (Hars et al. 2000), and frequency of access (i.e., popularity) (Hope, 1999).

Basic mechanisms for cataloging, searching, and payment should be developed to support community management and interactions among members.

Advanced mechanisms would support transactions for knowledge creation, sharing, and evaluation. Examples of such mechanisms include auctions for knowledgeintensive information products, accumulation of evaluations of knowledge products, and monitoring of knowledge base access. Other advanced transaction mechanisms include decision aids such as software agents and recommendation systems. We believe that decision aid tools will be used more frequently in virtual than in physical communities.

\section{Integration}

The primary implementation model for the C-KLASS environment is a digital library enhanced with a suite of tools or services, such as the ones we propose for virtual community knowledge support. At NJIT we currently are developing a service infrastructure for digital libraries that will allow us to "plug in" tools and their respective repositories (Bieber et al. 2001). The concepts developed by NJIT's on-going Dynamic Hypermedia Engine project (Bhaumik et al. 2001; Bieber 1998; Galnares 2001) will facilitate automated interlinking, and enable each tool to operate upon the elements of the other tools. This involves mapping all objects within any C-KLASS system as a subclass of a node or mapping each to a node, which then all tools can operate upon. Essentially a node is an "element of interest" (Bieber, 1990). In many traditional hypermedia systems, only documents would be considered nodes. C-KLASS will encompass an extremely broad view of nodes. Integration will enable for example, community members to annotate or discuss any document, conceptual knowledge structure or step 
within a workflow. Conceptual knowledge structures could highlight the relationships among processes, link in memos and meeting notes concerning these, and include discussion threads about each. A guided tour could illustrate a particular process (e.g., developing a new course, conducting an election within the professional society, conducting a debate within the community through C-KLASS features), annotating each part of it, and link in related documents and discussions.

\section{Working with Testbed Communities}

The proposed research would follow the methods and best practices of action research (Avison et al., 1999; Baskerville \& Wood-Harper, 1996; Davidson et al., 2000). The professional societies anchoring each testbed community will organize the document-based content development of their Web sites and digital libraries using C-KLASS prototype tools and knowledge structures. An adequate set of starting materials will have to be provided to capture people's imaginations immediately. Otherwise, many will never come back and it will be difficult to build a critical mass. A good user interface that can support diverse sets of users is also imperative. For these reasons a small pilot should be run in each community before full implementation.

Several deployment plans can be developed and tested. These include ways for (1) making the community aware of, advocating, and achieving a critical mass of $\mathrm{C}$ KLASS use; (2) managing and maintaining C-KLASS; and (3) sustaining C-KLASS service and use.

Management will involve finding a group of people willing to be responsible for different aspects, including establishing a help service. Some communities may require moderators or facilitators.

Community leaders will need to coordinate activities to ensure sustainability. They should be assisted by the development of measures of sustainability and of identification of factors that potentially influence this sustainability.

\section{Evaluation}

The evaluation of such a large scale research endeavor is challenging. Evaluation should focus on both individuallevel and community-level analyses. This is particularly important when the system itself is part of an explicit social structure, such as a community. In all phases of the evaluation, it will be necessary to explicitly isolate and assess each of the key planned features (collaborative knowledge structuring, advanced hypermedia features, workflow and process support, digital video, financial transaction support), and then use that information for design and use feedback.

\section{$\underline{\text { Research Propositions and Data Collection Methods }}$}

The research questions listed above will need to be refined into more specific hypotheses and measures after a full requirements analysis and consultation with the testbed communities.

Following the tenets of action research, the evaluation will iteratively move through phases of theory generation and hypothesis testing throughout the study. (In conventional studies, researchers try to limit active intervention. In "action research" researchers use their skills or knowledge to help the participants successfully implement a social change, and/or to achieve their objectives.) Developing and validating suitable measures will constitute a major contribution to digital libraries and virtual community research. The most enduring contributions will probably be knowledge of what kinds of features and policies best support virtual communities of scholars - knowledge which can be applied to the design and operation of future systems with more advanced features.

\section{Evaluation Techniques}

The evaluation of the proposed virtual community support environment should contain both formative and summative elements and employ both qualitative and quantitative methods (Friedman \& Wyatt 1997; Kaplan \& Duchon 1998). Formative evaluation will help iteratively assess and improve the C-KLASS prototype's functionality and usability. Summative evaluation will assess usage, impacts, and satisfaction, in general, and the extent to which the research objectives are achieved.

Both quantitative and qualitative approaches are important. Qualitative research conducted through interviews, direct observation, and acquisition of other "non-numeric data", facilitates understanding of the social, political and organizational aspects of the community (Markus 1983). The research needs to address both the individual and community levels of analysis. This is particularly important when the system itself is part of an explicit social structure, such as a community.

\section{Formative Evaluation: Requirements Analysis}

The researchers should work closely with the participating user communities to specify C-KLASS requirements through documentary analysis (e.g., meeting minutes), semi-structured interviews with community leaders, and focus groups and participant observation. (The initial requirements analysis relates to Research Questions A2, A3, B2, C1, C2 and C3 above). 


\section{Formative Evaluation: Usability Testing}

User participation to inform the design and functionality of a computer system is important for increasing satisfaction and actual subsequent use of the finished system. When the first partial prototypes are ready, usability testing should be conducted using several qualitative methods. These include cognitive walkthroughs with all of the members of the research team and groups from the user community. When the revised prototype is ready, a usability testing procedure such as protocol analysis should be used (Benbunan-Fich 2001). The results of these procedures can be fed back to the design team as suggested improvements to both the interface and the functionality of the system. In addition, as early prototypes are deployed, brief on-line surveys will periodically query users for feedback about what they like or dislike, and what C-KLASS is missing. (Usability testing relates to Research Questions A3, B1, $\mathrm{B} 4$ and $\mathrm{C} 3$.)

\section{$\underline{\text { Summative Evaluation }}$}

Summative evaluation involves the following questions. How is the system actually integrated into the types of work it is supposed to support, and what cognitive issues exist (Gasser, 1986)? What are the impacts of a system such as C-KLASS, not only on the productivity of the individual users, but also on the growth of knowledge and social networks in the community as a whole, and on the nature and extent of intra and inter-disciplinary communication (Hiltz, 1984)? What problems arise with widespread implementation? What social and ethical issues are raised by systems of these types? Do members benefit more from being part of an intellectual community of users rather than individuals? Can establishing an e-marketplace so that users of content can be charged, support the continued development of the web sites? What fosters sufficient social value (users, information, resources) to stimulate continued adoption, use, and contribution by a critical mass in a virtual community?

Other studies have covered aspects of virtual community performance. These include studies of contributions to collective databases, sharing of solutions to organizational problems (Gilly, Stevenson \& Yale, 1991), motivations for posting to bulletin boards (Rafaeli \& LaRose, 1993), diffusion of electronic mail systems (Rice, 1990), and collecting and providing access to organizationallyrelevant individual expertise (Stevenson \& Gilly, 1993; Stein \& Zwass, 1995). These are among the questions that can be explored in the "summative" assessments of the proposed research system. Direct observation of online behavior (through text analysis and automatic monitoring of level of activity), semi-structured interviews, and sample surveys of users and of the wider professional society memberships, can be designed to focus on Research Questions A1, B1, B3, B4, C2, and D1 to D6.

An overall theoretical model of anticipated system impacts and a final set of specific hypotheses about impacts of certain system features should be developed after the completion of prototyping and usability testing. At this stage, we know both the initial system implementation and the expectations of prospective users. After the system is implemented, observations by community members and semi-structured interviews with users and community leaders, can help identify perceived benefits and problems with the system (Hiltz, 1994). The evaluation techniques can employ Web-based sample surveys of users, administered in a longitudinal design to track changes in behavior and attitudes over time. Annual survey of the membership of the target user communities can be used to find out why some members are not using the system.

Finally, C-KLASS should provide automatic tracking of use patterns. Longitudinal profiles of usage will come from this activity log.

\section{$\underline{\text { Instrumentation }}$}

Existing research instruments should be used to assess factors such as physical and cognitive access, implementation process, innovation attributes such as relative advantage and complexity, user needs, social influences such as supervisor's or coworkers' attitudes, initial expectations, cognitive styles, domain expertise, symbolic value, potential for losses or gains in personal and positional power (Ehrlich, 1987; Kraut, Rice, Cool \& Fish, 1998; McKenney et al. 1992; Perin,1991; Rice \& Gattiker, 1999). Some portions of these instruments may be embedded as features in the system, such as a short pop-up diagnostic survey or request for recommendations. Summative evaluations will include the salient factors from the formative evaluation as predictors and control variables in explaining outcomes.

\section{In Closing}

To investigate knowledge-sharing and learning in virtual communities, this paper proposes a comprehensive research program involving the development of a prototype system followed by in-depth social and technical analyses of the performance of the system in one or more real virtual communities. From an examination of the literature, we developed a set of research questions and a set of requirements for virtual community support. We described a proposed software system, C-KLASS, comprising a set of integrated (and inherently extensible) tools for supporting collaboration, knowledge sharing and learning for distributed 
communities. We then described how this system would be deployed and evaluated in a real virtual learning community. These evaluative elements themselves constitute a major research contribution for this domain.

Our proposed research strategy should enable the development of a number of guidelines for facilitating knowledge sharing and learning, including methods for developing, managing, maintaining, promoting and sustaining virtual community support. While we focus here on the virtual communities surrounding professional societies, our proposed support for knowledge sharing and learning should transfer relatively easily to other virtual communities including educational communities, and business and non-profit organizations. All of these communities and organizations have multimedia documents, processes and discussions, and all potentially could take advantage of C-KLASS and its associated procedures to achieve knowledge sharing and learning.

\section{$\underline{\text { Acknowledgements }}$}

We gratefully acknowledge funding by the United Parcel Service, by the NASA JOVE faculty fellowship program, by the New Jersey Center for Multimedia Research, by the National Center for Transportation and Industrial Productivity at the New Jersey Institute of Technology (NJIT), by the New Jersey Department of Transportation, and by the New Jersey Commission of Science and Technology.

\section{References}

Avison, David, Francis Lau, Michael D. Myers and Peter Axel Nielson. (1999). Action Research, Communications of the ACM, Vol. 42, No. 1, 94-97.

Baskerville, R.L. and Wood-Harper, A.T. (1996). A Critical Perspective on Action Research as a Method for Information Systems Research. Journal of Information Technology (11), 235-246.

Benbunan-Fich, R. (2001) Using protocol analysis to evaluate the usability of a commercial web site. Information \& Management, forthcoming.

Bernstein, Abraham (1998). Executing Programs with Varying Degrees of Specificities: Populating the Spectrum of Specificity. Internal Report. Cambridge, MA: Center for Coordination Science - MIT.

Bhaumik, Anirban, Deepti Dixit, Roberto Galnares, Manolis Tzagarakis, Michalis Vaitis, Michael Bieber, Vincent Oria, Aparna Krishna, Qiang Lu, Firas Aljallad, Li Zhang (2001). Integrating Hypermedia Functionality into Database Applications, Proceedings of HICSS 2001.

Bieber, M. (1990). Generalized Hypertext in a Knowledgebased DSS Shell Environment, Ph.D. Dissertation, University of Pennsylvania.
Bieber, M. (1998). Hypertext and Web Engineering. Proceedings of the Ninth ACM Conference on Hypertext and Hypermedia, ACM Press, 277-278.

Bieber, M., Galnares, R. and Lu, Q. (2001). Service Integration for Virtual Communities. Web Engineering Workshop, International World Wide Web 10 Conference, Hong Kong, May 2001.

Bieber, Michael, Douglas Engelbart, Richard Furuta, Starr Roxanne Hiltz, John Noll, Jenny Preece, Edward Stohr, Murray Turoff and Bartel Van De Walle (2002). Towards Virtual Community Knowledge Evolution. Journal of Management Information Systems (forthcoming).

Bieber, M., Vitali, F., Ashman, H., Balasubramanian, V.and Oinas-Kukkonen, H. (1997). Fourth Generation Hypermedia: Some Missing Links for the World Wide Web. International Journal of Human Computer Studies 47, 31-65.

Borgman, Christine L. (1999). From Gutenberg to the Global Information Infrastructure: Access to Information in the Networked World, MIT Press.

Bos, N., Gergle, D., Olson, J. S. \& Olson, G. M. (2001) Being there versus seeing there: Trust via video. CHI 2001 Extended Abstracts, 291-292.

Brown, J. R., van Dam, A., Earnshaw, R., Encarnacao, J., Geudj, R., Preece, J., Shneiderman, B., Vince, J. (1999) Human-centered computing, online communities, and virtual environments. IEEE Computer Graphics and Applications. 19, 6, 70-74.

Card, S. K., Mackinlay, J. D. \& Shneiderman, B. (1999) Readings in Information Visualization. Using Vision to Think. Morgan Kaufmann Publishers Inc. San Francisco.

Choo, C.W. (1995). Information management for the intelligent organization: The art of scanning the environment. Medford, NJ: Information Today, Inc.

Cicourel, A. (1990). The integration of distributed knowledge in collaborative medical diagnosis. In J. Galegher, R. Kraut \& C. Egido (Eds.) Intellectual teamwork: Social and technological foundations of cooperative work. (pp. 221242.) Hillsdale, NJ: Erlbaum.

Connolly, T. \& Thorn, B. (1990). Discretionary databases: Theory, data, and implications. In J. Fulk \& C. Steinfield (Eds.) Organizations and communication technology. (219233.) Newbury Park, CA: Sage.

Davenport, T. \& Prusak, L. (1998). Working knowledge: How organizations manage what they know. Boston, MA: Harvard Business School Press.

Davison, R.M., Qureshi, S., de Vreede, G.J., Vogel, D.R. and Jones, A.N. (2000). Group Support Systems Through the Lens of Action Research: Experiences in Organisations, Journal of Global IT Management, 3, 4, 6-23.

Ehrlich, S. (1987). Strategies for encouraging successful adoption of office communication systems. ACM Transactions on Office Information Systems, 5(4), 240-357.

Friedman, CP and Wyatt, JC, eds. (1997). Evaluation Methods in Medical Informatics. New York: Springer. 
Gaines, B. R., Chen, L.-J. L., and Shaw, M. L. G. (1997) Modeling the Human Factors of Scholarly Communities Supported Through the Internet and the World Wide Web. Journal of the American Society of Information Science, 48(11), 987-1003

Galnares, R. (2001), Dynamically Generating Metainformation, Ph.D. Dissertation, New Jersey Institute of Technology, August 2000.

Gilly, M. C., Stevenson, W. B. \& Yale, L. J. (1991). Dynamics of complaint management in the service organization. The Journal of Consumer Affairs, 25(2), 295-323.

Goldman-Segall, R. (1998). Points of Viewing Children's Thinking: A Digital Ethnographer's Journey. NJ, Lawrence Erlbaum Publishers.

Goldman-Segall, R., \& Rao, Srinivasan V. (1995). Capturing Stories in Organizational Memory Systems: The Role of Multimedia. Proceedings of the Hawaii International Conference on System Sciences (HICSS), Hawaii.

Goldman-Segall, R., Rao, Srinivasan V. (1998). A Collaborative On-Line Digital Data Tool for Creating Living Narratives in Organizational Knowledge Systems, Proceedings of the Hawaii International Conference on System Sciences (HICSS), Hawaii.

Hagel III, J. \& Armstong, A. G. (1997) Net Gain; Expanding markets through virtual communities. Harvard Business School Press: Boston: MA.

Harasim, Linda, Hiltz, Roxanne, Teles, Lucio, and Turoff, Murray. (1995). Learning Networks: A field guide to teaching and learning online, MIT Press.

Hars, A., El Sawy, O., Gosain, S., Im, I., Kang, D., Lee, Z., Prasser, S. and Raven, A (2000). Reengineering IS research for the electronic economy. Journal of Organizational Computing and Electronic Commerce, 10(2), 67-83.

Hiltz, S.R. (1984). Online Communities: A Case Study of the Office of the Future. Norwood NJ: ABLEX Publishing Corp., Human-Computer Interaction Series.

Hiltz, S. R. (1986). The Virtual Classroom: Using ComputerMediated Communication for University Teaching. J. of Communication, 36,2 (Spring): 95-104.

Hiltz, S. R. (1994). The Virtual Classroom: Learning Without Limits Via Computer Networks. Norwood, NJ, Ablex Publishing Corp.

Hiltz, S. R. and Wellman, B. (1997). Asynchronous Learning Networks as Virtual Communities. Communications of the ACM, Sept. 1997.

Hope, Julian (1999). Knowledge services: Where self service and value added services co-exist. Business Information Review, 16(1), 38-43.

Hutchins, E. (1991). Organizing work by adaptation. Organizational Science, 2, 14-39.

Jones, S. (1999) Studying the net: Intricacies and issues. In S. Jones (Ed.) Doing Internet Research. Sage Publications: Thousand Oaks, CA. 1-27.

Kaplan, B. and Duchon, D. (1998). Combining qualitative and quantitative methods in information systems research: A case study. Management Information Systems Quarterly, 12: 571-586.

Kling, R. (1996) Social relationships in electronic forums: Hangouts, salaons, work-places and communities. In R. Kling (Ed.) Computerization and Controversy: Value Conflicts and Social Choices. (Second Ed.) Academic Press: San Diego: CA.

Kollock. P. (1999) The economies of online cooperation: gifts and public goods in cyberspace. In. M. A. Smith and P. Kollock Communities in Cyberspace. Routledge London. 220-239.

Koschmann (1996), CSCL, Theory and Practice of an emerging paradigm. 1-23.Mahwah, NJ: Lawrence Erlbaum.

Kraut, R., Rice, R.E., Cool, C. \& Fish, R. (1998). Varieties of social influence: The role of utility and norms in the success of a new communication medium. Organization Science, 9(4), 437-453.

Linn, M. C. (1995) Designing Computer Learning Environments for Engineering and Computer Science: The Scafolded Knowledge Integration Framework. Journal of Science Education and Technology, 4:2:103-126.

Majchrzak, A., Rice, R.E., Malhotra, A., King, N., \& Ba, S. (2000). Technology adaptation: The case of a computersupported inter-organizational virtual team. MIS Quarterly, December (in press.)

March, J. C. (1999). The pursuit of organizational intelligence. Malden, MA: Blackwell Business.

Markus, M.L. (1983). Power, Politics and MIS Implementation. Communications of the ACM, 26, 430-444.

McCown, R. R. \& Driscoll, M. P. (1995). Using Collaborative Writing and Problem-Based Learning in the College Classroom. Proceedings of the Computer Supported Collaborative Learning Conference, 1995.

McKenney, J., Zack, M., \& Doherty, V. (1992). Complementary communication media: A comparison of electronic mail and face-to-face communication in a programming team. In N. Nohria \& R. Eccles (Eds). Networks and organizations: Structure, form and action. (pp. 262-287.) Boston, MA: Harvard Business School Press.

Mowshowitz, Abbe. (1995). Virtual Organizations: A Vision of Management in the Information Age, The Information Society, Volume 10, 267-294.

Nonaka, Ikujiro. (1994). A dynamic theory of organizational knowledge creation, Organization Science, 5(1), 14-37.

O'Neill, D. K., \& Gomez, L. M. (1994). The collaboratory notebook: A distributed knowledge-building environment for project-enhanced learning. In Proceedings of Ed-Media '94, Vancouver, BC.

Perin, C. (1991). Electronic social fields in bureaucracies. Communications of the ACM, 34(12), 75-82.

Perkins, D.N. (1993). Person-plus: A distributed view of thinking and learning. In G. Salomon (Ed). Distributed Cognitions: Psychological and Educational Considerations pp. 88-111.Cambridge: Cambridge University Press. 
Preece, J. (1999). Empathic Communities: Balancing Emotional and Factual Communication. Interacting with Computers The Interdisciplinary Journal of HumanComputer Interaction. 12, 1, 63-77.

Preece. J. (2000). Online Communities: Designing Usability, Supporting Sociability. Chichester, England: John Wiley.

Rafaeli, S. \& LaRose, R. (1993). Electronic bulletin boards and public goods explanations of collaborative mass media. Communication Research, 20(2), 277-297.

Rice, R.E. (1990). Computer-mediated communication system network data: Theoretical concerns and empirical examples. International Journal of Man-Machine Studies, 30, 1-21.

Rice, R.E., Collins-Jarvis, L. \& Zydney-Walker, S. (1999). Individual and structural influences on information technology helping relationships. Journal of Applied Communication Research, 27(4), 285-303.

Rice, R.E., \& Gattiker, U. (2000). New media and organizational structuring of meanings and relations. In F. Jablin and L. Putnam (eds.) New handbook of organizational communication. (pp. 544-581) Newbury Park, CA: Sage.

Rice, R.E. \& Katz, J. (Eds.) (2001). The Internet and health communication. Thousand Oaks, CA: Sage.

Robey, D., Boudreau, M-C., and Storey, V.C. (1998). Looking Before We Leap: Foundations for a Research Program on Virtual Organizations, Electronic Commerce: Papers from the Third International Conference on the Management of Networked Organizations, G. St-Amant and M. Amami (eds.), 275-290.

Sanchez \& A. Heene (eds.) (1997). Strategic learning and knowledge management. (pp. 163-187.) Chicester, UK: Wiley.

Scardamalia, M., Bereiter, C., Brett, C., Burtis, P.J., Calhoun, C., \& Smith Lea, N. (1992). Educational applications of a networked communal database. Interactive Learning Environments, 2(1), 45-71.

Shneiderman, Ben (2000) Universal Usability. Communications of the ACM 43(5), 84-91.

Spender, J-C. (1998). Pluralist epistemology and the knowledge-based theory of the firm. Organization, 5(2), 233-256.

Spiro, R. J., Feltovich, P. J., Jacobson, M. J. \& Coulson, R. L. (1991). Cognitive Flexibility, Constructivism, and Hypertext. Educational Technology, May 1991, pp. 24-33.

Sproull, L. and Kiesler, S. (1991) Connections. New ways of working in the networked organization. MIT Press, Cambridge: MA.

Stahl, G. (1999). Reflections on WebGuide: Seven Issues for the Next Generation of Collaborative Knowledge-Building Environments In Proceedings of the Computer Support for Collaborative Learning (CSCL) 1999 Conference, C. Hoadley \& J. Roschelle (Eds.) Dec. 12-15, Stanford University, Palo Alto, California. Lawrence Erlbaum.

Stein, E.W. and V. Zwass. (1995). Actualizing Organizational Memory with Information Technology. Information Systems Research Vol. 6, No. 2: 85-117.
Stevenson, W. B. \& Gilly, M. (1993). Problem-solving networks in organizations: Intentional design and emergent structure. Social Science Networks, 22, 92-113.

Suthers (1999). Representational Support for Collaborative Inquiry. Proceedings of the 32nd Hawai'i International Conference on the System Sciences (HICSS-32), January 58, 1999, Maui, Hawai'i (CD-ROM), Institute of Electrical and Electronics Engineers, Inc. (IEEE).

Tichy, N. \& Fombrun, C. (1979). Network analysis in organizational settings. Human Relations, 32(11), 923-965.

Turoff, Murray (1997). Virtuality, Communications of the ACM, Volume 40, Number 9, 38-43.

Turoff, Murray and Hiltz, S.R. (1995). Computer Based Delphi Processes, in Michael Adler and Erio Ziglio, editors., Gazing Into the Oracle: The Delphi Method and Its Application to Social Policy and Public Health, London, Kingsley Publishers, pp. 56-88.

Turoff, M. and Hiltz, S.R. (2001). Effectively managing large enrollment courses: A case study. In In J. Bourne an J.C. Moore, eds., Online Education, Volume 2: Learning Effectiveness, Faculty Satisfaction and Cost Effectiveness. Needham, MA., Sloan Center for Online Education, 55-80.)

Turoff, M., Hiltz, R., Bieber, M., Rana, A., Fjermestad, J. (1999). Collaborative Discourse Structures in Computer Mediated Group Communications, Proceedings of the 32nd Hawaii International Conference on System Sciences.

Turoff, Murray, Starr Roxanne Hiltz, Michael Bieber, Brian Whitworth and Jerry Fjermestad. (2001). Computer Mediated Communications for Group Support: Past and Future, (John Carroll, ed.) in Human-Computer Interaction in the New Millennium, Addison Wesley, forthcoming.

Vygotsky, L. (1962). Thought and language. Cambridge, MA. MIT Press.

Walsh, J. P., \& Ungson, G. R. (1991). Organizational memory. Academy of Management Review, 16(1), 57-91.

Wellman, (1997) An electronic group is virtually a social network. In S. Kiesler Culture of the Internet. Lawrence Earlbaum Associates: Mahwah, NJ. 179-208.

Wellman, B. (1983). Network analysis: Some basic principles. In R. Colins (Ed.) Sociological theory 1983. (155-200.) SF: Jossey-Bass.

Wenger, E. (1998). Communities of practice: The social fabric of a learning organization. NY, NY: Cambridge U. Press.

Zhao, J., Kumar, A. and Stohr, E. (2000). A Workflow-Centric Model of Organizational Knowledge Distribution.

Proceedings of the 33rd Hawaii International Conference on System Sciences. 